\title{
Doença de Van Neck-Odelberg - Entidade rara ou subdiagnosticada?
}

\section{Van Neck-Odelberg Disease - A Rare or Underdiagnosed Condition?}

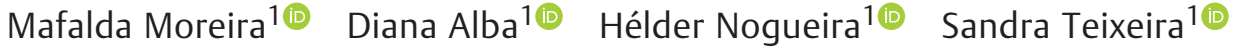 \\ ${ }^{1}$ Serviço de Pediatria e Neonatologia, Centro Hospitalar do Tâmega e \\ Sousa, Penafiel, Portugal \\ Endereço para correspondência Mafalda Moreira, Interna de \\ Pediatria, Centro Hospitalar do Tâmega e Sousa, Porto, Portugal \\ (e-mail: mafalda.moreira@campus.ul.pt).
}

Rev Bras Ortop

\begin{abstract}
Resumo
A doença de Van Neck-Odelberg (VNO) é uma osteocondrose rara, que acomete a sincondrose isquiopúbica (SIP). Esta entidade deve ser incluída no diagnóstico diferencial de crianças com claudicação na marcha, dor inguinal e limitação funcional do quadril. Imagiologicamente é caracterizada por hipertrofia assimétrica da SIP. Apresentamos o caso clínico de uma criança de 4 anos, previamente saudável, atendida no serviço de emergência devido a dor inguinal no lado esquerdo e claudicação na marcha com início no mesmo dia. Não havia história prévia de trauma ou alteração dos parâmetros inflamatórios. Foi realizada uma radiografia da bacia e ressonância magnética nuclear (RMN) que evidenciou imagem radiopaca de contornos bem definidos no ramo isquiopúbico esquerdo e edema na SIP. Com diagnóstico provável de doença de VNO, o paciente foi medicado sintomaticamente, com resolução completa ao fim de 10 dias. A claudicação na marcha é um motivo frequente de avaliação médica na população pediátrica. Até os 5 anos de idade, as causas mais comuns são sinovite transitória do quadril, artrite séptica e Doença de Legg-CalvéPerthes. Na ausência de história de trauma ou clínica sugestiva de infeção deverá ser equacionada a hipótese de doença de VNO. Para o seu diagnóstico, é fundamental a realização de radiografia da bacia, cujo achado mais comum é uma opacificação

Palavras-chave

- osteocondrose

- criança

- claudicação intermitente fusiforme unilateral, no nível do ísquion, podendo ser necessária a realização de RMN. $O$ tratamento recomendado é conservador, com recuperação sintomática em 2 semanas. O conhecimento e o diagnóstico desta entidade permitem uma abordagem direcionada e sem a carga emocional para o paciente e seus familiares que outras patologias poderiam transmitir.
\end{abstract}

Trabalho realizado no Centro Hospitalar do Tâmega e Sousa, Penafiel, Portugal.

recebido

14 de Dezembro de 2020

aceito

11 de Fevereiro de 2021
DOI https://doi.org/

10.1055/s-0041-1739402. ISSN 0102-3616. (c) 2022. Sociedade Brasileira de Ortopedia e Traumatologia. All rights reserved.

This is an open access article published by Thieme under the terms of the Creative Commons Attribution-NonDerivative-NonCommercial-License, permitting copying and reproduction so long as the original work is given appropriate credit. Contents may not be used for commercial purposes, or adapted, remixed, transformed or built upon. (https://creativecommons.org/ licenses/by-nc-nd/4.0/)

Thieme Revinter Publicações Ltda., Rua do Matoso 170, Rio de Janeiro, RJ, CEP 20270-135, Brazil 


\begin{abstract}
Van Neck-Odelberg (VNO) disease is a rare osteochondrosis affecting the ischiopubic synchondrosis (IPS). This condition should be included in the differential diagnosis of children with lameness, inguinal pain, and functional limitation of the hip. In imaging tests, it is characterized by asymmetric IPS hypertrophy. We present the clinical case of a 4-year-old child, previously healthy, who visited the emergency department for left inguinal pain and lameness starting on the same day. There was no previous history of trauma or changes in inflammatory parameters. The patient underwent a pelvic radiography and magnetic resonance imaging (MRI), which revealed a radiopaque image with well-defined contours in the left ischiopubic branch, and IPS swelling. With a presumed diagnosis of VNO disease, the patient was medicated symptomatically, with complete recovery in 10 days. Lameness is a frequent reason for medical evaluation in the pediatric population. In subjects up to 5 years old, the most common causes of lameness include transient hip synovitis, septic arthritis, and Legg-Calvé-Perthes disease. In the absence of a history of trauma or infection-related clinical findings, VNO disease should be considered as a hypothesis. Its diagnosis requires a pelvic radiography, usually showing a unilateral fusiform opacification at the ischial level; an MRI may be necessary. The recommended treatment is conservative, with symptomatic recovery in 2 weeks. The knowledge and diagnosis of VNO disease allow a targeted approach, without the emotional burden for the patient and his/her family that may be associated to other conditions.
\end{abstract}

\section{Introdução}

As osteocondroses, também denominadas por alguns autores como osteocondrites, resultam de alterações da ossificação endocondral, no nível dos núcleos ósseos em desenvolvimento nas epífises e apófises. ${ }^{1,2}$ A sua etiologia permanece desconhecida; contudo, alterações vasculares e microtraumáticas parecem estar na sua origem. ${ }^{2}$ Predominam na infância e na adolescência, estando associadas a surtos de crescimento e alterações hormonais. As osteocondroses mais frequentes são a doença de Köhler, doença de Freiberg, doença de Sever e doença de Osgood-Schlatter, sendo a osteocondrite isquiopúbica ou doença de Van Neck-Odelberg (VNO) uma osteocondrose raramente diagnosticada. ${ }^{1}$

A osteocondrite isquiopúbica foi descrita inicialmente em 1923 por Van Neck, sendo depois complementada em 1924 por Odelberg, sendo hoje conhecida como doença de Van NeckOdelberg. ${ }^{3,4}$ É uma patologia benigna e auto-limitada, que se caracteriza pela evidência imagiológica de hipertrofia assimétrica da sincondrose isquiopúbica (SIP), associada a claudicação na marcha, dor inguinal unilateral e limitação funcional do quadril. ${ }^{3,4}$ Os diagnósticos diferenciais a considerar são a fratura de estresse, patologia infeciosa, nomeadamente osteomielite, ou neoplásica, sendo necessária, em alguns casos, a realização de ressonância magnética nuclear (RMN). 3,5,6

\section{Relato do Caso}

Uma criança do sexo feminino, de 4 anos, previamente saudável, foi atendida no serviço de emergência devido a um quadro com 24 horas de evolução de claudicação na marcha e dor na região inguinal esquerda, de agravamento progressivo. Sem febre, sintomatologia constitucional ou sinais inflamatórios locais e sem história prévia de trauma ou intercorrência infeciosa recente. Ao exame objetivo, destacava-se dor na mobilização do quadril, sem sinais inflamatórios locais.

Foi realizado um estudo analítico, com hemoleucograma, velocidade de sedimentação (VS) e proteína C-reativa (PCR) sem alterações de relevo. A radiografia da bacia evidenciou imagem radiopaca, com cerca de $1.8 \times 1.4 \mathrm{~cm}$, de contornos bem definidos, no nível do ramo isquiopúbico esquerdo (-Figuras 1 e 2). Para esclarecimento etiológico, foi realizada

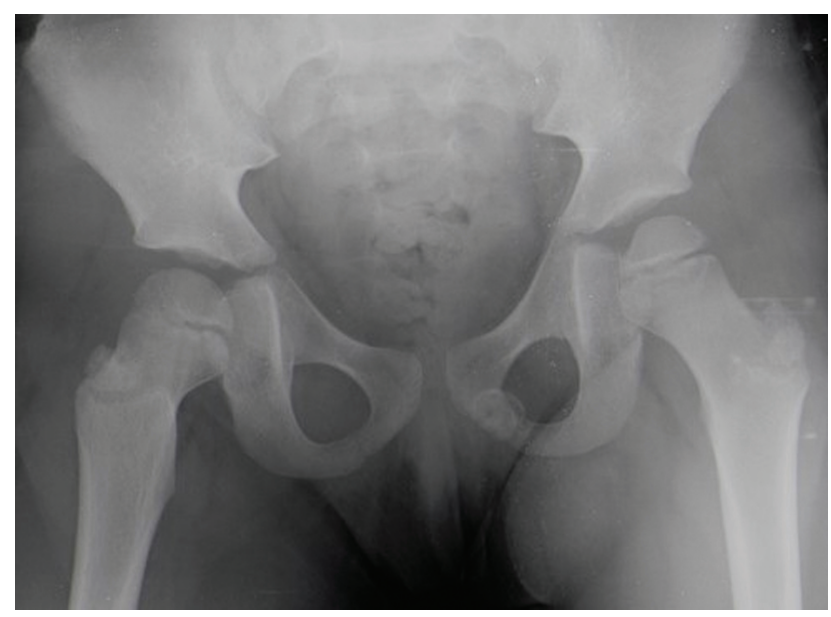

Fig. 1 Radiografia da bacia (incidência ântero-posterior): imagem radiopaca no nível do ramo isquiopúbico esquerdo, de contornos bem-definidos. 


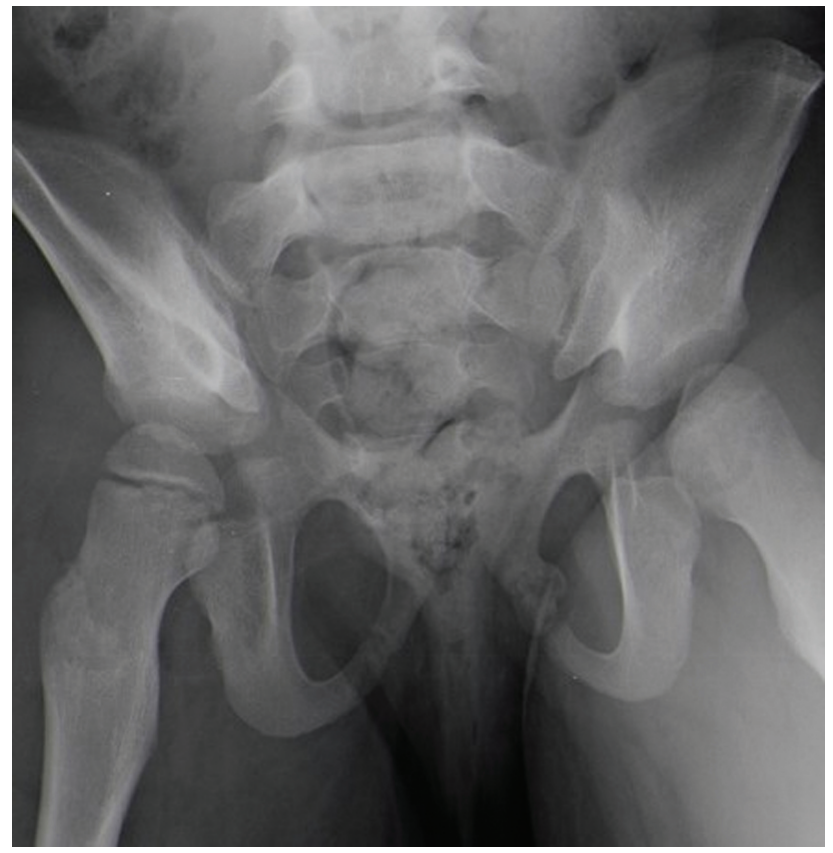

Fig. 2 Radiografia da bacia (outlet).

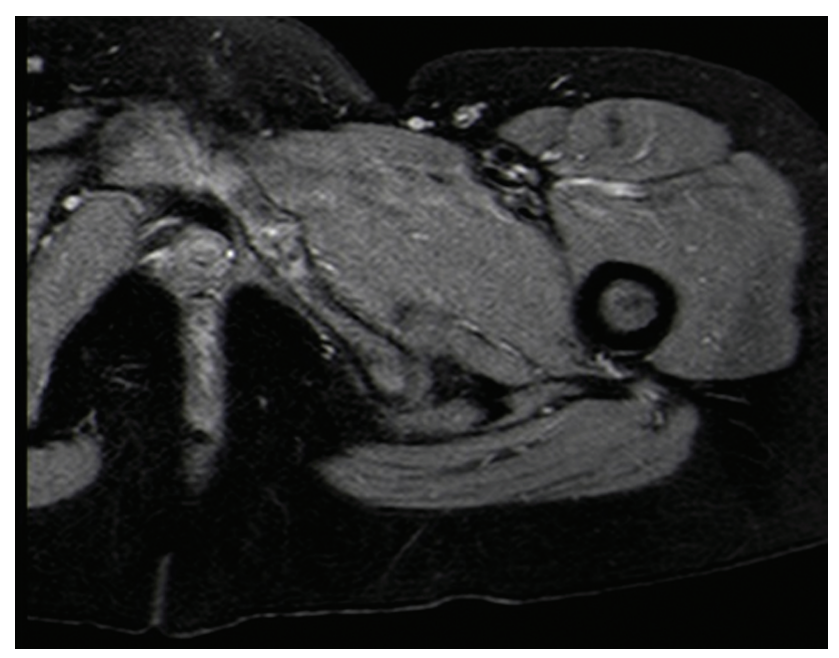

Fig. 3 Ressonância magnética da bacia: edema a nível da sincondrose isquiopúbica esquerda.

RMN da bacia, que revelou presença de edema a nível da sincondrose isquiopúbica esquerda, sem alterações dos tecidos moles envolventes (-Figura $\mathbf{3}$ ).

Excluídas as hipóteses de etiologia infeciosa ou tumoral, foi presumido diagnóstico de doença de VNO, e a paciente foi medicada sintomaticamente, com anti-inflamatório oral e indicação para repouso. Dez dias após, ela foi reavaliada clinicamente, encontrando-se sem queixas.

A radiografia da bacia foi repetida seis meses depois do episódio inicial, verificando-se remodelação completa da área de lesão (-Figura 4). Não houve ocorrência de novos episódios.

\section{Discussão}

A claudicação na marcha é uma queixa frequente na população pediátrica, sendo o seu diagnóstico diferencial muito

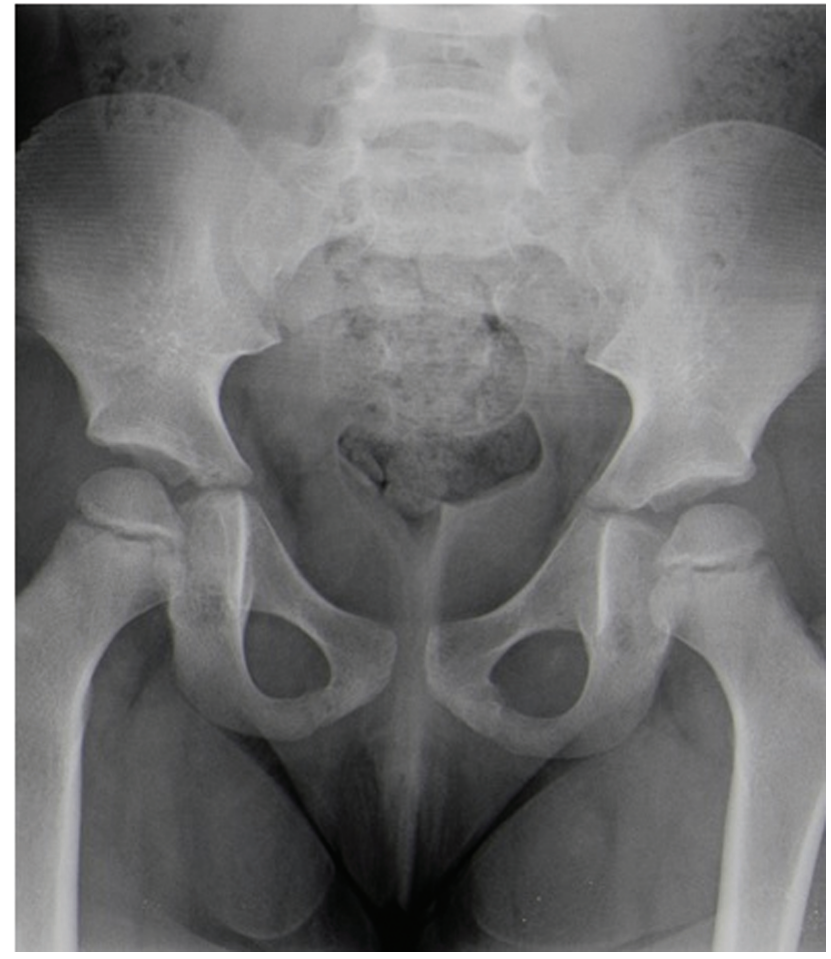

Fig. 4 Radiografia da bacia (incidência ântero-posterior): resolução imagiológica completa.

desafiante, atendendo a múltiplas etiologias possíveis, variáveis de acordo com a faixa etária considerada. Em crianças que apresentam dor unilateral na região inguinal, associada à limitação da mobilidade do quadril, sem febre, história de trauma ou infeções recentes, é importante que seja equacionada a hipótese de doença de VNO. ${ }^{6}$

Esta patologia resulta do processo de ossificação assimétrico da SIP, que, habitualmente, tem início na infância e término antes da adolescência. ${ }^{5}$ Na maioria dos casos, ela não causa sintomas; contudo, em algumas crianças pode surgir dor na região inguinal ou glútea, bem como limitação da mobilidade articular.

Normalmente, a doença de VNO é mais frequente no membro inferior não dominante, na maioria dos casos o esquerdo, como no caso que apresentamos. Alguns autores explicam este fato pelo peso corporal ser principalmente suportado pelo membro inferior não dominante, comparativamente com o contralateral, que é utilizado preferencialmente para executar os movimentos. ${ }^{3,5}$ Este desequilíbrio de forças poderia causar o atraso do encerramento da sincondrose isquiopúbica no lado não dominante, e este, por sua vez, mediante estresse mecânico, tornar-se-ia doloroso. ${ }^{3,5}$

A osteocondrite de VNO é um diagnóstico de exclusão em crianças com quadro de claudicação na marcha. ${ }^{6}$ Para o seu diagnóstico, é fundamental a realização de radiografia da bacia, cujo achado mais comum consiste na presença de opacificação fusiforme unilateral no nível do ísquion. Atendendo ao aspeto pseudo-tumoral que a hipertrofia da SIP pode assumir, pode ser necessária a realização de RMN para diagnóstico diferencial. ${ }^{7}$ Apesar de não constituir critério de diagnóstico de doença de VNO, a ausência de elevação 
analítica de parâmetros inflamatórios, nomeadamente leucócitos, PCR e VS, apoia esta hipótese. ${ }^{6,8}$

O tratamento conservador, com terapêutica anti-inflamatória e repouso, é o mais recomendado, estando associado à evolução clínica favorável e ao desaparecimento das queixas em cerca de 2 a 3 semanas., ${ }^{3,5}$ A resolução imagiológica é mais prolongada, podendo levar de meses a 1 ano. ${ }^{3}$ Quando se completa a ossificação, a deformidade desaparece da junção isquiopúbica. É importante salientar que achados radiológicos com atraso da fusão da SIP em crianças assintomáticas não levam ao diagnóstico de osteocondrite isquiopúbica, constituindo um processo fisiológico normal. ${ }^{5}$

Por outro lado, o conhecimento e diagnóstico da doença de Van Neck-Odelburg, de natureza benigna e auto-limitada, permitem uma abordagem direcionada e sem a carga emocional para o doente e seus familiares que outras patologias poderiam transmitir.

\section{Suporte Financeiro}

Não houve suporte financeiro de fontes públicas, comerciais, ou sem fins lucrativos.

\section{Conflito de interesses}

Os autores declaram não haver conflito de interesses.

\section{Referências}

1 Danger F, Wasyliw C, Varich L. Osteochondroses. Semin Musculoskelet Radiol 2018;22(01):118-124

2 West EY, Jaramillo D. Imaging of osteochondrosis. Pediatr Radiol 2019;49(12):1610-1616

3 Chaudhari AP, Shah G, Patil SS, Ghodke AB, Kelkar SB. Van NeckOdelberg Disease: A Rare Case Report. J Orthop Case Rep 2017;7 (01):24-27

4 Akkari M, Waisberg G, Reis Braga S, et al. Osteocondrite de Van Neck-Odelberg. Relato de 4 casos. Rev Bras Ortop 2010;45:55-58

5 Oliveira F. Differential diagnosis in painful ischiopubic synchondrosis (IPS): a case report. Iowa Orthop J 2010;30(Suppl):195-200

6 Ferreira J. Van Neck-Odelber Disease: a rare cause of childhood limping. Nascer Crescer 2019;28(04):223-227

7 Morante Bolado I, Ortega Navaridas M, Clemente Garulo D, López Robledillo JC. Enfermedad de Van Neck-Odelberg: una causa más de cojera en la infancia. Reumatol Clin 2017;13(05): 299-300

8 Wait A, Gaskill T, Sarwar Z, Busch M. Van neck disease: osteochondrosis of the ischiopubic synchondrosis. J Pediatr Orthop 2011;31(05):520-524 